\section{Behavioural And Social Science Research}

\section{P4.01 ASSESSMENT OF COMPREHENSIVE HIVIAIDS KNOWLEDGE LEVEL AMONG IN-SCHOOL \& COMMUNITY LEVEL ADOLESCENTS OF NOAKHALI AND LAKSHMIPUR DISTRICT, BANGLADESH}

Abdur Rashid. Marie Stopes and Bapsa Consortium Project, Noakhali and Lakshmipur, Bangladesh

\subsection{6/sextrans-2017-053264.498}

Introduction In Noakhali and Lakshmipur, more adolescents are in school and community today than ever before; however, there are no studies that have assessed their comprehensive knowledge of HIV/AIDS. Thus, this study tried to assess the level of this knowledge and the factors associated with it among in-school and community level adolescents in Noakhali and Lakshmipur district.

Methods A cross-sectional school and community- based study was conducted using a facilitator-guided self-administered questionnaire conducted April 2016. The respondents were students attending regular school in 14 high schools and 70 community level adolescents located in 14 different Sub-districts in Noakhali and Lakshmipur district. The proportion of adolescents with comprehensive HIV/AIDS knowledge was computed and compared by sex. The investigating tool used was a prepared, pretested questionnaire. This had both openand close-ended questions related to various aspects of HIV/ AIDS. Different factors related to HIV/AIDS and information was gathered. The subjects were assessed for knowledge of various aspects of HIV/AIDS and associated risk factors. It was subsequently followed by an open discussion on HIV/ AIDS with the students. The factors that were associated with the comprehensive HIV/AIDS knowledge were assessed using multivariable logistic regression.

Results Only about one in four, 677 (24.5\%), in-school adolescents and community level adolescents have comprehensive HIV/AIDS knowledge. The knowledge was better among inschool adolescents from families with a relatively middle or high wealth index (adjusted OR [95\% CI] $=1.39$ [1.03-1.87] and 1.75 [1.24-2.48], respectively), who got HIV/AIDS information mainly from friends or mass media (adjusted OR $[95 \% \mathrm{CI}]=1.63[1.17-2.27]$ and 1.55 [1.14-2.11], respectively) and who received education on HIV/AIDS and sexual matters at school (adjusted OR $[95 \% \mathrm{CI}]=1.59 \quad[1.22-2.08]$ ). The females were less likely to have comprehensive HIV/AIDS knowledge compared to males (adjusted OR and [95\% CI] $=0.60[0.49-0.75])$.

Conclusion In general, only about a quarter of in-school adolescents had comprehensive HIV/AIDS knowledge. Although the female adolescents are highly vulnerable to HIV infection and its effects, they were by far less likely to have comprehensive HIV/AIDS knowledge. HIV/AIDS information, education and communication activities need to be intensified in high schools and rural community.

\section{P4.02 EFFECTS OF A RESTRICTIVE STATE LAW ON STD/HIV RATES IN OHIO}

${ }^{1}$ Abigail Norris Turner, ${ }^{1}$ Courtney N Maierhofer, ${ }^{1}$ Maria F Gallo, ${ }^{2}$ Carolette Norwood, ${ }^{2}$ Danielle A Bessett, ${ }^{1}$ Alison H Norris. 'Ohio State University, Columbus, USA; ${ }^{2}$ University of Cincinnati, Cincinnati, USA

\subsection{6/sextrans-2017-053264.499}

Introduction In recent years, Ohio has enacted multiple laws that impact sexual and reproductive health. In February 2016, a new law came into effect, which prohibits the state from contracting health services with any organisation that performs or promotes abortion. This law blocks funding of organisations such as Planned Parenthood from receiving state funds for activities related to HIV and STD testing and sexual education.

Methods We are conducting a rigorous evaluation of the sexual and reproductive health-related consequences of the new law. In an ecologic analysis of state- and county-level data from Ohio for 2015 and 2016, we will compare trends in prevalence of HIV, chlamydia and gonorrhoea (all nationally notifiable conditions) before and after the implementation of the2016 law. We will examine trends by several characteristics, including sex, race/ethnicity, age, education level, insurance status (Ohio is a Medicaid-expansion state under the Affordable Care Act), sexual orientation, urban/rural residence, and other variables. To disentangle the effect of the law from secular trends in HIV/STD, we will compare Ohio's outcomes to the same outcomes in nearby Illinois. Illinois has similar population characteristics to Ohio but does not have the same legislative environment impacting allocation of funds for reproductive health services.

Results Results will be available in summer 2017. In Ohio, we anticipate a decline in the number of HIV and STD tests performed in 2016 compared to 2015, and an increase in the prevalence of each disease in 2016 compared to 2015 . We anticipate no meaningful changes in trends across years in Illinois.

Conclusion Multiple states across the United States are considering legislation similar to Ohio's, to restrict the use of state and federal funding by clinical and community organisations that provide HIV/STD care alongside other sexual health services. Determining the HIV/STD-related impacts of such laws is critical to avoid putting men and women at higher risk of disease.

\section{P4.03 OPTIMISING DEVELOPMENT, IMPLEMENTATION AND EVALUATION OF STI/HIV PREVENTION INTERVENTIONS IN SUB-SAHARAN AFRICAN SCHOOLS: A QUALITATIVE STUDY WITH RESEARCHERS}

${ }^{1}$ Abubakar Sadiq Sani, ${ }^{1}$ Charles Abraham, ${ }^{1}$ Denford Sarah, ${ }^{2}$ Catherine Mathews. 'University of Exeter, Exeter, UK; ${ }^{2}$ South African Medical Research Council - Cape Town, South African Republic

\subsection{6/sextrans-2017-053264.500}

Introduction Existing trials show limited effectiveness of school-based sexual health interventions (SBSHI) in preventing sexually transmitted infections (STI) including HIV in subSaharan Africa (sSA). Limitations in content, implementation or evaluation are some reasons for this limited effectiveness. We explored facilitators and challenges to designing, implementing and evaluating SBSHI in sSA. 